icb erst in späterer Zeit darauf aurïckkomuen. Es gowährt ein besonderes Interesse, fïr die Tage von Juli bis 23 die l,age des Cometen, des Schweife, und der Sonoe in einer Coustruction zu überblicken. um zo gewabren, wie der untere Theil des Schweifs vor der Sonne vorübergeht, und welche ung ‘wöhnliche Iage der Scbweif in Beziehung ant die Sonne unter gewissen Bedingungen einzullelimen vermag.

Athen, den 3. Noreuber 1875.

J. F. .Julius Sirhmidt.

Schrriben des Herrn Dr. Schellen an den Herausgeber.

Es wird den Astronomen diesseits des Oceans von Interesse sein, 211 erfahren. dass die Regierung der Vereinigten Staateu Nordamerika a zum ersten Male einem Gelebrten eine goldene Verdienstmedaille gewidmet hat. Die Commission für die Beobahtung des Venuodurcbgangs bat nämlich in Anerkennung der grossen Diesste, welche Herr Henry Draper, Protessor der Chemie an der Universität 2u Newyork, wïhrend der monatelangen Vorbereitungen fur die photographischen Aufoahmen der Erscheinung ihr gelcistet hat, eine grosse. goldene Medaille überreicht, welclse in der Stantsinün\%e zu Philadelphia geprägt worden ist. - Die Avcrsseite trägt in der Mitte das Bild des ron Draper angewandten Heliostats unit der Umschrift: „Faurau extendere factis hoc virtutis opus est" (Virg. Aell.). Dic Reversseite entbält in der Mitte die Inscbrift: ${ }_{n}$ Veneris in sole spectandac Curatores R. P. F. S., Henrico Dra.

per, M. D. -.. Der. VIIl. MDCCCLXX1V«, und die Imschrift: „Virtus virtuti addit avito" (eine Anspielung ant die hervorragenden wissenschaftlicten Arbeiten seines Vaters John W. Draper). Die Medaille, 6 Centimeter im Durihmesser, war von cinur reich verzierten und in Form eines Buches cingebundenen Adresse beglcitet; der eine Deckel des Buchs dient zugleioh als Bebälter für dic Mrdaille. - Wir wollen nicht unerwähnt lassen, dass scitens der nordamerikaniscien Regierung cine ähnliche Belolinung des herrurragenden Verdieustes bereits fruber Cyrus W. Field z.n Theil gewordell ist; aber es geschab diesey aut eivem andern Gebiet, dem rler Legung der atlantischen Telegraphenkabel. Draper ist der crste Gelehrte, der für seine verdienstvollen Arbeiten aut dem Gicbiet der Himmelsphotographie cine solithe ehrende Auszeichnung erbalten hat.
Dr. Schellen.

\title{
Entdeckung eines neuen Planeten (156).
}

Telegraphisclie Depesclic des Ilerr" Professor Fnerster an den Herausgeber.

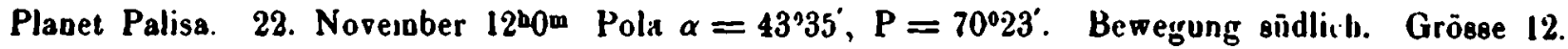

Berlin, den 23. November 1875.

Foerster.

\section{Berichtigungen.}

Im 1. Baud weiner Ausgabe von Besscl's Abhandlungen sind einige Druckfchler stehen geblieben, un deren gefällige Bericlstigung in Ihren Astr. Nachr. ich Sie ersuchen möchte:

Seite XXV, Spalte 2, Zeile 11 vou unten, statt 1850 ist zu lesen 1858,

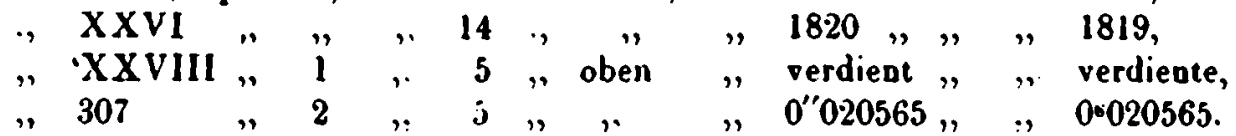

Leiprig, den 14. November 1875.

A. Engelmann.

\section{Verkäutliches Liniversalinstrument.}

Ein in gutem Lustand befindliches zehnzblliges Universalinstrament von Pistor und Martins ist bei dem Meclianiker A. Bonsack in Berlin, Prinzenstrasse 27, z.1m Preise von 900 Mark zu verkanfen.

\section{In balt:}

2. Nr. 2005 - 206i. E. Srlionfeld. Beiträge zur Kenniniss des Lichtwechsels veranderlicher Sterne. I. - J. F. Julius Schmide. Beob. achlungen uber den grossen Conielen int Jalire 1874. 33. - Dr. Schellen. Schreiben all den Herausgeber. 47. - Fuerster. Entdeckung eines neven Planelen. (156). 47. - K. Eugelmann. Berichtigungen. 17. - Verkauliches Universalinstrumeni. 47. 